\title{
India's Nuclear Minimalism: Looking Through the Smokescreen
}

\author{
Ayesha Abbasi*
}

\begin{abstract}
Nuclear minimalism calls for a limited utility of nuclear weapons as objects of ensuring security. It is a concept not commonly debated. However, it has remained an important part of India's strategic thought and the country continues to struggle with maintaining a balance between the concept and its increasing nuclear ambitions. In fact, New Delhi's rapid strategic developments prove that nuclear minimalism has been used as a smokescreen to allow it to pursue these developments. This article seeks to understand the contours of India's nuclear doctrine through the prism of nuclear minimalism and its (in)efficacy in keeping nuclear expansion in check.
\end{abstract}

Keywords: Nuclear Minimalism, South Asia, No First Use, Massive Retaliation, Disarmament, Credible Minimum Deterrence.

\section{Introduction}

$\mathrm{P}$ ositive image building is ingrained in the DNA of every single human being. Similarly, all nation states aspire to acquire a positive image among the comity of nations. However, after witnessing the lethality of nuclear weapons in 1945, major powers hurried to acquire this capability to ensure not just their security but also status. Yet, they did not

* The author is Research Fellow at the Center for International Strategic Studies (CISS), Islamabad, Pakistan. She can be contacted at: ayeshaabbasi1990@gmail.com.

@ 2019 by the Islamabad Policy Research Institute.

IPRI Journal XIX (2): 35-59.

https://doi.org/10.31945/iprij.190202.

IPRI JOURNAL — SUMMER 2019 


\section{Ayesha Abbasi}

forsake their desire of projecting a positive image, and hence, advocated disarmament in good faith - but in due time - as part of the nuclear Non-Proliferation Treaty (NPT). This was done while furthering the narrative that highlighted acquisition of nuclear weapons as taboo.

Historically, nuclear weapon states (NWS) opted for various means to paint a positive image, and continue to do so. This is either done by projecting themselves as heroes and their adversaries as villains speaking from a position of weakness and citing the need to protect national integrity as a driver behind NW acquisition - or by opting for policies like No First Use (NFU). Another behaviour common to the NWS is their call for other states to abstain from pursuing similar weapons, while committing themselves to the goals of eventual disarmament - without committing to a specific timeline.

Nuclear minimalism is one such concept - projected by Indian scholars as an important part of India's strategic culture ${ }^{1}$ - used as a means to portray itself as a responsible NWS, which acquired nuclear weapons reluctantly. The concept has been used by India in the past to describe its nuclear posture, and its understanding of the utility of nuclear weapons. This article aims to understand this concept in detail, while linking it with the Indian case and whether the country's nuclear policies are in line with the basic tenets of minimalism.

\section{Defining Minimalism}

There are two main schools of thought dealing with nuclear strategy that became prominent during the Cold War. One was the Maximalist School, and the other was the Minimalist School of Deterrence Theory. The maximalists believed in maintaining counterforce superiority and aimed to

\footnotetext{
${ }^{1}$ Rajesh M. Basrur, "Nuclear Weapons and Indian Strategic Culture," Journal of Peace Research 38, no. 2 (2001): 184, http://www.jstor.org/stable/425494; Sarang Shidore, "India's Strategic Culture and Deterrence Stability on the Subcontinent," in Deterrence Instability \& Nuclear Weapons in South Asia, eds. Michael Krepon et al. (Washington D.C.: Stimson Center, 2015), 119-148, https://www.stimson.org/sites/default/files/fileattachments/Deterrence_Instability_WEB.pdf; and, Vipin Narang, "Five Myths about India's Nuclear Posture," Washington Quarterly 36, no. 3 (2013): 143-157, doi:10.1080/0163660x.2013.825555.
} 
conventionalise nuclear weapons. ${ }^{2}$ Implying, that they were basically conventional weapons with extremely high catastrophic consequences. Maximalism finds its roots in the Minimalist School, wherein the latter outlines the need to understand that no political gain is worth the destruction that is inherent in a nuclear war. ${ }^{3}$ The second assertion by the Minimalist School is that nuclear weapons should only be considered as tools to maintain deterrence which can be achieved with merely a limited number as well. ${ }^{4}$ The concept of Minimum Deterrence is also a derivative of this school of thought.

Through these definitions, a basic difference drawn between Minimalism and Credible Minimum Deterrence (CMD) could be that in the former, the number of minimum weapons can be quantified implying, that if a state requires only one weapon to deter its adversary, it does not have to further enhance its arsenal. However, Credible Minimum Deterrence - a dynamic concept - provides some flexibility to carry out developments to enhance credibility in response to developments by an adversary, and thus, is difficult to quantify. ${ }^{5}$ In other words, it would not be wrong to say that a CMD posture essentially provides grounds for quantitative and qualitative improvements, which occur in response to the adversary's developments.

\section{India's Quest for Nuclear Weapons}

The Sino-Indian War of 1962, Chinese nuclear weapon tests two years later, and security threats from Pakistan are highlighted by India as the drivers behind its acquisition. However, one may assert that the country had taken its first step towards these weapons when work began on the Bhabha Atomic Research Center (BARC) in 1954. The Canada India Reactor Utility Services - more commonly known by its acronym, CIRUS - provided under the Atom for Peace initiative was the primary

\footnotetext{
${ }^{2}$ Eric K. Graben, "Superpower Nuclear Minimalism in the Post-Cold War Era?," Arms Control 13, no.3 (1992): 352-374, doi:10.1080/01440389208403997.

${ }^{3}$ Ibid., 3 .

${ }^{4}$ Ibid.

${ }^{5}$ Farah Zahra, "Credible Minimum Nuclear Deterrence in South Asia," IPRI Journal XII, no. 2 (2012): 1, http://www.ipripak.org/wp-content/uploads/2014/01/art1fars12.pdf.
} 


\section{Ayesha Abbasi}

source of the weapon-grade plutonium that was used for India's first nuclear explosion in $1974 .^{6}$

Raja Ramana, who was made head of BARC after the death of Homi Bhabha and served as BARC's head between 1972-78, ${ }^{7}$ sidelined the considerations of maintaining a deterrent when he stated:

There was never a discussion among us over whether we shouldn't make the bomb. How to do it was more important. For us, it was a matter of prestige that would justify our ancient past. The question of deterrence came much later. Also, as Indian scientists we were keen to show our Western counterparts, who thought little of us those days, that we too could do it. ${ }^{8}$

This is a brief example of how Indian policy-makers remained consumed by their desire to project their country as a technologically advanced state, while trying to highlight that it was a reluctant entrant into the club of NWSs. This dichotomy in approach is discussed in detail in the successive paragraphs.

\section{Evolution of India's Nuclear Policy: Journey from Minimalism to Maximalist Approach}

\section{Nehruvian Minimalism}

Historically, drawing from the attributes of minimalism, India's nuclear doctrine has been categorised as being minimalist in nature. Existing literature on the subject suggests that Indian nuclear minimalism came into being at the time of independence. This was primarily because of Mahatma Gandhi's relentless advocacy for peace and later, India's first

6 Atomic Heritage Foundation, "Indian Nuclear Program," accessed March 24, 2019, https://www.atomicheritage.org/history/indian-nuclear-program.

7 Atomic Heritage Foundation, "Raja Ramanna," accessed April 17, 2019, https://www.atomicheritage.org/profile/raja-ramanna.

8 Nuclear Weapons Archive, "India's Nuclear Weapons Program - The Beginning: 19441960," accessed March 25, 2019, http://nuclearweaponarchive.org/India/IndiaOrigin.html. 
Prime Minister Jawaharlal Nehru's scepticism of nuclear weapons even when he realised their importance in world politics. This resulted in an evolution of Indian strategic thought - in the coming two decades, till the 1960s - to be marred with suspicion towards nuclear weapons. The Hiroshima-Nagasaki bombing two years prior to India's independence further cemented apprehensions. However, while Nehru reportedly rejected the proposition to acquire nuclear weapons, he remained open to the idea. ${ }^{9}$

T. T. Poulose describes Nehru's view of nuclear weapons by stating that, 'there was no guile in his [Nehru's] nuclear policy ... Nehru's nuclear decisions were not the outcome of any national debate but deeply rooted in his ... abhorrence of nuclear weapons and nuclear allergy after the supreme tragedy at Hiroshima and Nagasaki.' 10

The minimalistic nuclear approach is also rooted in Nehru's statements like the one he made at Lok Sabha in 1957, wherein he said that:

[W]e have declared quite clearly that we are not interested in and we will not make these bombs, even if we have the capacity to do so. ${ }^{11}$

However, an analysis of his later statements show a clear dichotomy in words and actions. This was also seen as being the underlying theme in one of his speeches in Bombay in 1946, where he stated:

As long as the world is constituted as it is, every country will have to devise and use the latest scientific devices for its protection. I have no doubt India will develop her scientific researches and I hope Indian scientists will use the atomic force for constructive purposes. But if India is threatened she

9 Rajesh Basrur, "India's Nuclear Arsenal: Prospects for Enlargement," in Nuclear Doctrines and Strategies: National Policies and International Security, eds. Mark Fitzpatrick, A. I. Nikitin and Sergeĭ Oznobishchev (Amsterdam: IOS Press, 2008), 129.

${ }^{10}$ George Perkovich, India's Nuclear Bomb: The Impact on Global Proliferation (Berkeley: University of California Press, 1999), 13.

11 Ibid. 
Ayesha Abbasi

will inevitably try to defend herself by all means at her disposal. $^{12}$

This duality by Nehru may be reasoned in two ways, (a) being the immediate successor to Gandhi, he could not let his image be tarnished by supporting a technology as violent as nuclear weapons; and (b) there was no imminent threat to Indian security in Nehru's time as Prime Minister which could provide justification for their development. However, while he projected a pacifist image, he hired Dr Homi J. Bhabha - to initiate India's nuclear energy programme - who was later to become the father of India's nuclear bomb. Such duality of approach continues in Indian policy-making. This has been recognised as an effective approach by India's policy-makers and is succinctly put by a senior Indian defence official - quoted by George Perkovich in his book — when he wrote:

[T]he Hindu mind does not accept the 'either/or', 'black or white', 'yes or no' template of the West. We prefer 'greys and browns' and 'yes and no.' ${ }^{13}$

Smiling Buddha is another testament of India's dichotomous narrative building. India misused the technology and instead of utilising it for peaceful applications, it was used to build a bomb while projecting it as a 'peaceful' explosion. However, as one of India's leading physicist and former Minister of State for Defence, Raja Ramanna pointed out:

The Pokhran test was a bomb, I can tell you now - an explosion is an explosion, a gun is a gun, whether you shoot at someone or shoot at the ground - I just want to make clear that the test was not all that peaceful. ${ }^{14}$

\footnotetext{
${ }^{12}$ Ibid., 14.

${ }^{13}$ Ibid.

${ }^{14}$ Dipankar Banerjee, "Addressing Nuclear Dangers: The Confidence-building between India, China and Pakistan," in The Politics of Nuclear Weapons in South Asia, ed. Bhumitra Chakma (London: Ashgate Publishing Ltd., 2013), 196.
} 
India's Nuclear Minimalism: Looking Through the Smokescreen

\section{Minimalism Post-(Overt) Nuclearisation}

According to various sources - India's strategic circles used the phrase 'minimum deterrence' to describe the country's nuclear posture prior to its overt nuclearisation in 1998. The phrase 'minimum deterrence' may have been used to signify the presence of an existential deterrence. It has been noted in various writings that India could not have opted for any other posture because it lacked capabilities such as a credible delivery system, early warning and surveillance systems, and an effective command and control (C2) structure which could ensure a credible nuclear deterrence. ${ }^{15}$

The approach of nuclear minimalism continued to feature prominently in national nuclear discourse, especially in the statements of Indian strategic analyst K. Subrahmanyam, who was also a front-running proponent of this concept. In his words, 'nuclear weapons were not weapons of war; they were political weapons.'16 Additionally, he countered the Cold War theology of having ready-to-use weapons by proposing that India could do without nuclear weapons as they are only political instruments, and huge amounts of money can be saved with the retention of only a small strategic force because deterrence is bound to 'decay over the next couple of decades for sheer lack of utility of the nuclear arsenal. ${ }^{17}$ It was because of such an understanding of nuclear weapons that some factions in India continued to look down upon them with cynicism - much in line with Nehruvian thought.

The Nehruvian approach formed the cornerstone of India's stance on nuclear weapons once debate about the country's nuclear doctrine began after it became overtly nuclearised in 1998. One of India's leading strategic analysts, Rajesh Basrur describes India's strategic culture as having three main contours:

\footnotetext{
${ }^{15}$ Naeem Salik, The Genesis of South Asia Nuclear Deterrence (Karachi: Oxford University Press, 2009), 43.

${ }^{16}$ Ayesha Ray, The Soldier and the State in India: Nuclear Weapons, Counterinsurgency, and the Transformation of Indian Civil-Military Relations (New Delhi: SAGE Publications, 2013), 70.

${ }^{17}$ Bharat Karnad, India's Nuclear Policy (Connecticut: Greenwood Publishing Group, 2008), 87.
} 
Ayesha Abbasi

(a) a very limited acceptance of the utility of nuclear weapons as a source of national security; (b) a political rather than a technical understanding of nuclear weapons (nuclear weapons do deter, and yet are 'non-useable'); and (c) restrained responses to pressures either to enhance or reduce national nuclear capabilities. ${ }^{18}$

So, theoretically, India maintains a minimalist value of nuclear weapons as part of its security equation in the region and does not rely heavily on them. This also designates a political function to this technology, thereby making them necessary only as deterring objects since their potential implications are too significant to ignore - which in turn render them non-usable.

This view explains why the civilian policy-makers' perception about the utility of nuclear weapons only fell into the category of use as a political tool, necessary to leverage political influence. Moreover, this affirms that one of the reasons behind opting for nuclear minimalism as an approach was that the majority of policy-makers involved in the decisionmaking process lacked technical understanding of these weapons. While they did understand the consequences associated with their use, they also realised that these weapons held the necessary power to ensure security. ${ }^{19}$

\section{India's Nuclear Doctrine}

National Security Advisor Brajesh Mishra — on August 17, 1999 released a Draft Nuclear Doctrine (DND), ${ }^{20}$ generally regarded as the first documented account of the country's nuclear policy. The DND continues to guide the contours of nuclear policy and arsenal development to date despite being an unofficial document. While the earlier reiterations about

\footnotetext{
${ }^{18}$ Basrur, "Nuclear Weapons and Indian Strategic Culture", 184.

${ }^{19}$ Ibid.

${ }^{20}$ MoEAI "Draft Report of the National Security Advisory Board (NSAB) on the Indian Nuclear Doctrine," Ministry of External Affairs India, August 17, 1999, https://mea.gov.in/in-focusarticle.htm?18916/Draft+Report+of+National+Security+Advisory+Board+on+Indian+N uclear+Doctrine.
} 
nuclear weapons capability and related policy were tied to the concept of minimalism, this was not as prominent in the DND.

However, India later tried to reconcile its commitments in the DND with nuclear minimalism which was underscored in Jaswant Singh's interview in November 1999 as Minister of External Affairs, which is considered to be an authentic and comprehensive presentation of doctrine. He noted that:

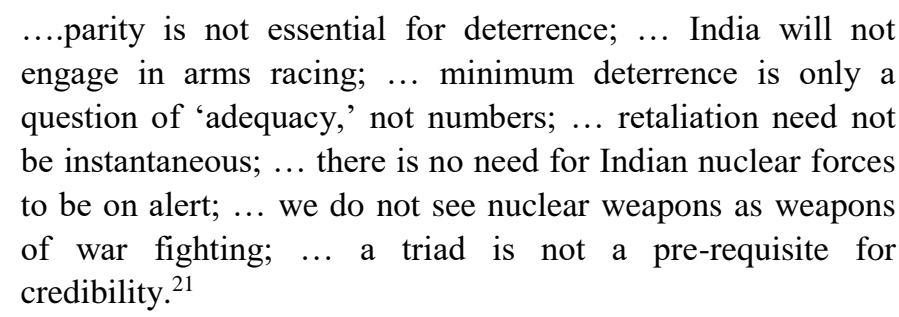

While the DND was not considered an official policy document, another doctrinal statement - generally referred to as 'press statement' released in January 2003 - did little to assuage queries related to India's nuclear doctrine. Three main commitments or tenets - which were a variation from the 1999 DND - could be identified in the 2003 statement; No First Use (NFU), massive retaliation in response to any first strike - be it with nuclear, chemical, or biological weapons - and Credible Minimum Deterrence (CMD).

Another commitment was to abide by India's interest in arms control measures,${ }^{22}$ with the help of a proposal encompassing 'continued commitment to the goal of a nuclear weapons free world, through global,

\footnotetext{
${ }^{21}$ Basrur, "India's Nuclear Arsenal: Prospects for Enlargement," 131; Acronym Institute for Disarmament Diplomacy, "Interview with Jaswant Singh- Minister of External Affairs,” November 29, 1999, http://www.acronym.org.uk/old/news/199911/interviewjaswant-singh-minister-external-affairs; Prabhu Chawla and Raj Chengappa, "I Believe this Country cannot be Constructed through Demolitions: Jaswant Singh," India Today, January 11, 1999, https://www.indiatoday.in/magazine/interview/story/19990111-ibelieve-this-country-cannot-be-constructed-through-demolitions-jaswant-singh-7798491999-01-11.

22 Ibid.
} 


\section{Ayesha Abbasi}

verifiable and non-discriminatory nuclear disarmament. ${ }^{23}$ Despite these commitments, India failed to sign the NPT which remains the cornerstone of the global nuclear non-proliferation regime. The prestige which drove India's quest for nuclear weapons was also a deciding factor when it came to joining the NPT. India viewed it as discriminatory which provided existing NWSs with a power currency in the form of nuclear weapons, while forcing others to abstain from acquiring similar technology. ${ }^{24}$ India could have chosen to sign the NPT if it really believed in the goal of global disarmament, and if it did not find any utility for nuclear weapons to strengthen its defence. The other five NWSs also endorse the goal of global disarmament. However, they acquired nuclear weapons before NPT came into force, and since NPT does not put any tangible restrictions on their status as NWS. However, the same cannot be said for India's case, which had the chance to champion disarmament goals by becoming a part of the NPT; yet it chose not to do so and opted to acquire nuclear capability.

The following sections seek to address these major contours of India's nuclear doctrine. These will be seen through the lens of India's proclaimed commitment to nuclear minimalism and whether the actions on ground presently align with this philosophy of the country's strategic thought.

\section{Minimalism versus CMD}

Even though Jaswant Singh made claims about continued commitment to minimalism, the duality of India's policy-making came into play once again when Singh categorically stated that 'minimum' in CMD cannot be a 'fixed physical quantification ... (rather is) dynamic concept ... firmly rooted in the strategic environment, technological imperatives and

${ }^{23}$ Rifaat Hussain, Nuclear Doctrines in South Asia, report (SASSU Research Report No. 4, Bradford: South Asian Strategic Stability Unit, 2005), http://sassi.org.pk/wpcontent/uploads/2017/03/Nuclear-Doctrines-in-South-Asia.pdf.

${ }^{24}$ A. Gopalakrishnan, "Evolution of the Indian Nuclear Power Program," Annual Review of Energy and the Environment 27, no. 1 (2002): 369-395, doi:10.1146/annurev.energy.27.122001.083448. 
national security needs $\ldots{ }^{25}$ Such contrast proves that inherently India's projection of being a proponent of nuclear minimalism and its declared policy of CMD are not in line with each other. While CMD is in fact an offshoot of the concept of minimalism the inherent difference lies in the quantification of weapons, and this distinction makes the two rather dissimilar in nature.

Indeed, the minimalistic posture - if implemented in its essence requires the state to maintain the least possible number of weapons to inflict sufficient damage to the adversary. The concept of CMD however, allows for the number of weapons to remain open-ended. Moreover, it also allows India's policy-makers to misuse the flexibility permitted by this concept and engage in an uncontrolled expansion of the country's nuclear capabilities beyond its security needs. ${ }^{26}$ This is becoming evident especially under the rule of current Bharatiya Janata Party (BJP) government, as will be explained in detail in the successive paragraphs.

\section{No First Use or 'No' No-First Use?}

It was in 1994 when the Government of India (GoI) delivered a non-paper to Pakistan and one of the agenda items included a proposition for an agreement on NFU of nuclear weapons. ${ }^{27}$ The NFU — in simplest of terms - is a commitment to abstain from using nuclear weapons, unless they are used by an adversary first. The policy of NFU, however, in no way undercuts the deterrent value of a country's nuclear arsenal - as existential deterrence always remains in play to prevent the adversary from undertaking any belligerent action. Concurrently, it is important to understand that NFU does not mean that nuclear weapons will never be used and are just acquired to deter an adversary from using its own nuclear arsenal. In fact, it is tacitly a nuclear use policy as opposed to merely being a deterrence posture. According to experts, the

${ }^{25}$ Acronym Institute for Disarmament Diplomacy, "Interview with Jaswant Singh, Minister of External Affairs, Hindu, November 29 1999," http://www.acronym.org.uk/old/archive/spsingh.htm.

${ }^{26}$ Ibid., 132.

${ }^{27}$ Kumar Sundaram and M. V. Ramana, "India and the Policy of No First Use of Nuclear Weapons," Journal for Peace and Nuclear Disarmament 1, no. 1(2018): 152-168, doi:10.1080/25751654.2018.1438737. 


\section{Ayesha Abbasi}

aforementioned proposal is probably the starting point of India's official declaration suggesting that it was abiding by the policy of NFU. ${ }^{28}$

India became overtly nuclearised with Pokhran II (also called Operation Shakti), which comprised of two groups of nuclear tests conducted on May 11 and 13, 1998. The first of the two groups comprised of a fission bomb, a sub-kiloton device and allegedly a thermonuclear device $^{29}$ - which was reportedly a failure. ${ }^{30}$ The second group consisted of two additional sub-kiloton devices. Since then, India has maintained the policy of nuclear NFU and the same was proposed in the DND. ${ }^{31}$ India was put under sanctions for its nuclear tests by the United States (US) and it was then engaged in negotiations - famously known as Talbott-Singh Talks, named after Indian Minister of External Affairs Jaswant Singh and Deputy Secretary of State of the US Strobe Talbott - with the aim to 'limit the development and deployment of its nuclear arsenal. ${ }^{32}$ Over time, said pressure gradually began to subside with India's identification of China as a major adversary - a proclamation which aligned with the US view of China as a revisionist power in the region which ought to be contained.

Such engagements with the US in the initial period as a nascent NWS should technically have made India cautious in implementing any drastic changes in its DND. However, it underwent changes in some important aspects which were evident in the 2003 press release. ${ }^{33}$ Two major alterations included the dilution of the NFU policy, and consequently, the Negative Security Assurance (NSA) pledge previously

28 Ibid.

29 Nuclear Weapons Archive, "India's Nuclear Weapons Program - Operation Shakti: 1998," accessed December 28, 2018, http://nuclearweaponarchive.org/India/IndiaShakti.html.

${ }^{30}$ Raj Chengappa, "Research by Western Scientists Contest India's Claims of Successfully Testing an H-Bomb," India Today, October 12, 1998,

https://www.indiatoday.in/magazine/cover-story/story/19981012-research-by-westernscientists-contest-indias-claims-of-successfully-testing-an-h-bomb-827192-1998-10-12.

${ }^{31}$ MoEAI "Draft Report of the National Security Advisory Board (NSAB) on the Indian Nuclear Doctrine."

32 Strobe Talbott, Engaging India: Diplomacy, Democracy, and the Bomb (Washington D.C.: Brookings Institution Press, 2004), 5.

33 "Cabinet Committee on Security Reviews Progress in Operationalizing India's Nuclear Doctrine,"Press Information Bureau Archive, January 4, 2003, http://pibarchive.nic.in/archive/releases98/lyr2003/rjan2003/04012003/r040120033.html 
taken. It is stated in the context of NFU that India may choose to opt for nuclear retaliation in the event of a 'major attack' even with chemical or biological weapons. ${ }^{34}$ The NFU, normally, calls for a retaliatory strike only when attacked with nuclear weapons. However, maintaining such a posture against a chemical or biological attack substantially reduces the credibility of this stance. Additionally, India also pledges to provide NSA to the NNWSs, which means that it would not use nuclear weapons against them. This alteration in the doctrine also undermined credibility of its NSA, as in such a scenario it would not matter if the aggressor is or is not a NWS. This clarifies the point that India's NFU cannot be taken as the final word, and if India believed in the reliability of such a position, it would have accepted China's NFU too and would not use it as a threat to justify the on-going massive expansion in its nuclear arsenal.

A few years after the release of its DND, India's leading strategist Bharat Karnad made two assertions about NFU. First, he contended that NFU is merely a peacetime declaration which is unlikely to be enforceable in reality as it is against the essence of nuclear capability to be kept solely for a second strike. Second, he asserted that NFU may be deemed plausible only in an extreme scenario where a country is highly confident of its ability to absorb and survive a first strike, while retaining sufficient forces to level a devastating retaliatory strike, all the while maintaining efficient crisis management systems. ${ }^{35}$

Furthermore, since 2014, Modi administration's oscillatory positioning on the (non)revision of NFU pledge further dilutes the credibility of India's commitment. BJP's commitment to 'study in detail India's nuclear doctrine, and revise and update it, to make it relevant to challenges of current times' in the 2014 election manifesto ${ }^{36}$ came as a surprise to many within and outside the country. Once this statement began sounding alarms, then-prime ministerial front-runner Narendra

\footnotetext{
${ }^{34}$ Rajesh Rajagopalan, “India's Nuclear Policy,” (paper presented at $12^{\text {th }}$ International Symposium on Security Affairs, Tokyo, November 18, 2009), http://www.nids.mod.go.jp/english/event/symposium/pdf/2009/e_06.pdf.

${ }^{35}$ Bharat Karnad, Nuclear Weapons \& Indian Security: The Realist Foundations of Strategy (New Delhi: Macmillan, 2002), 442.

${ }^{36}$ Bhartiya Janata Party Election Manifesto (2014), https://www.bjp.org/images/pdf_2014/full_manifesto_english_07.04.2014.pdf.
} 


\section{Ayesha Abbasi}

Modi recommitted his party to the NFU stating, 'No first use was a great initiative of Atal Bihari Vajpayee - there is no compromise on that. We are very clear ... No first use is a reflection of our cultural inheritance' ${ }^{37}$ - again trying to tie it with the contours of nuclear minimalism.

This recommitment was short-lived and was questioned once again when Indian Defence Minister Manohar Parrikar reportedly stated that a degree of 'unpredictability' should be there when it came to nuclear weapon use. While he continued to reiterate that it was his personal opinion and did not mirror the government policy, he criticised the NFU asking, 'Why should I bind myself?' ${ }^{38}$

While India - with such statements - may be trying to enhance the psychological dimension of threat perception in its neighbours, it is doing so at the expense of the credibility of its own nuclear capabilities and the claims of minimalism.

Another aspect of the DND - that goes against the minimalistic approach - is the objective of ensuring an 'assured capability to shift from peacetime deployment to fully employable forces in the shortest possible time. ${ }^{39}$ This implies that the forces will have to be kept in mated form - which is necessary for higher readiness and preparedness of the weapons. This ready arsenal may then be put on high alert, something in stark contrast to the posture of NFU and the overall ideals of minimalism.

Having said that, initially India did, in fact, keep its weapons demated, and warheads were kept away from delivery vehicles. This demated and de-alerted state is expected to be an important means to strengthen India's overall NFU policy. ${ }^{40}$ However, this changed when India opted for cannisterisation of its delivery systems. For instance, Agni-V, in its recent tests, was in closed configuration and launched from

\footnotetext{
37 “Modi Rules out BJP's will to Revise 'No-First-Use of Nukes' Policy,” Dawn, April 16 2014, https://www.dawn.com/news/1100300.

38 "Why Bind Ourselves to 'No First Use Policy', says Parrikar on India's Nuke Doctrine," Hindu, December 2, 2016, https://www.thehindu.com/news/national/Why-bindourselves-to-\%E2\%80\%98no-first-use-policy\%E2\%80\%99-says-Parrikar-onIndia\%E2\%80\%99s-nuke-doctrine/article16442100.ece.

${ }^{39}$ Ibid.

${ }^{40}$ Debalina Ghoshal, "India's Recessed Deterrence Posture: Prospects and Implications," Washington Quarterly 39, no. 1 (2016): 160, doi:10.1080/0163660X.2016.1170487.
} 
a cannister. ${ }^{41}$ Cannisterisation reduces launch time, and quick reaction options may entice the decision-maker to opt for nuclear launch if he sees that greater dividends against the adversary could be gained by striking first. Since de-mating is an important way to prevent unauthorised or accidental launch of a nuclear device, ${ }^{42}$ hence, it may be posited that cannisterisation makes the weapon systems prone to accidental or unauthorised use, as well as any other accidents to the delivery system itself.

\section{Massive Retaliation}

Massive retaliation is the third important aspect of India's nuclear doctrine which has been kept as an option in case the country is attacked with not only nuclear weapons, but even biological or chemical weapons by any state. While this response option not only dilutes the NFU pledge (which is already very unsteady as it is), it is a disproportionate response too - something which does not gel with the ideals of nuclear minimalism.

On the contrary, India - in the past - has made proclamations on international forums against the use of nuclear weapons. For instance, in response to International Court of Justice's (ICJ) Advisory Opinion in 1996 - which ruled that, 'the threat or use of nuclear weapons would generally be contrary to the rules of international law applicable in armed conflict, and in particular the principles and rules of international humanitarian law' - India submitted a Memorial arguing that 'nuclear weapons could not be used even if a country were to be attacked with nuclear weapons. ${ }^{43}$ The Memorial stated:

41 "India Successfully Test Fires Agni-5 Ballistic Missile," Hindu Business Line, January 18,2018 ,

https://www.thehindubusinessline.com/news/india-successfully-test-fires-agni5ballistic-missile/article10038902.ece.

${ }^{42}$ Gaurav Kampani, "Is the Indian Nuclear Tiger Changing its Stripes?," The

Nonproliferation Review 21, no. 3-4 (2014): 388, doi:10.1080/10736700.2015.1040230.

${ }^{43}$ Siddharth Mallavarapu, "A Mandate for Nuclear Prudence: International Court of Justice on Nuclear Weapons," in Prisoners of the Nuclear Dream, eds. M. V. Ramana and C. Rammanohar Reddy (New Delhi: Orient Longman, 2003), 245-269. 
Ayesha Abbasi

[t]he question... is whether the use of nuclear weapons would be lawful as a measure of reprisal or retaliation if the same is used by any adversary in the first instance. Reprisal or retaliation under international law are also governed by certain specific principles. First, reprisals to be valid and admissible could only be taken in response to a prior delict or wrongful act by a state. Second, such reprisals must remain within reasonable bounds of proportionality to the effect created by the original wrongful act... when a state commits such a wrongful act or depict, the use of force by way of reprisal would have to be proportionate and as such if the wrongful act did not involve the use of a nuclear weapon, the reprisal could also not involve the use of a nuclear weapon. ${ }^{44}$

The bottom line is that not only is India's massive retaliation approach at odds with this Memorial, its whole nuclear doctrine is a contradiction of such idealistic stances taken over time. This further shows that while India is trying to project its image as a responsible nation which realises the consequences of nuclear weapons and their use, on the sidelines, it is readying itself to become overtly nuclearised. Moreover, it was devising a weapon-use policy which not only sought nuclear use as a response to nuclear attack, but also in response to chemical and biological weapon use by an adversary - completely disregarding the element of proportionality.

\section{Enhanced Nuclear Modernisation}

While this may not be one of the main elements of India's nuclear doctrine, its increased investment in the development of its nuclear capabilities is a testament to its continued use of the ideals of minimalism as a smokescreen - behind which it continues to enhance nuclear capabilities, thereby, jeopardising the strategic stability of the whole region.

Again in contrast to the aforementioned Memorial to the ICJ and the stated policy in line with nuclear minimalism, the DND calls for investment in a triad of delivery means — including land-based missiles,

\footnotetext{
${ }^{44}$ Sundarama and Ramana, "India and the Policy of No First Use of Nuclear Weapons."
} 
sea-based assets, and aircrafts — which will be used to mount nuclear forces to launch 'punitive retaliation' to 'inflict damage unacceptable to the aggressor. ${ }^{, 45}$

According to the 2017 estimates by Stockholm International Peace Research Institute (SIPRI), India is working to construct six fast breeder reactors, which will supplement its ability to produce plutonium for new weapon systems. ${ }^{46}$ Moreover, the new unsafeguarded gas centrifuge facility called Special Material Enrichment Facility in Chitradurga will provide weapon-grade highly enriched uranium, which could be used to develop thermonuclear bombs in the future ${ }^{47}$ even though development of naval propulsion reactors is thought of as the primary driver behind India's quest for enhanced centrifuge enrichment capacity. ${ }^{48}$

A declared policy of NFU implies that India is willing to absorb a first strike and respond massively. This may be interpreted to mean that India - in choosing to deter by punishment - will opt for counter-value targets to inflict unacceptable damage instead of a counterforce strategy that targets nuclear or military infrastructure ${ }^{49}$ However, the recent debate on possible revision of NFU suggests that India is testing waters to implement a flexible response strategy. Flexible response will allow New Delhi to opt for either counter-value or counter-force targeting depending on the circumstances at hand. India may also opt for a pre-emptive counter-force attack against Pakistan if it thought that the latter was about to launch a nuclear weapon. India's aim, in this scenario, would be to fully disarm the country, and prevent Indian cities from being exposed to any nuclear counter-value attack emanating from Pakistan. ${ }^{50}$ This

${ }^{45}$ MoEAI "Draft Report of the National Security Advisory Board (NSAB) on the Indian Nuclear Doctrine."

${ }^{46}$ Shannon N. Kile and Hans M. Kristensen, Trends in World Nuclear Forces 2017, report (Stockholm: Stockholm International Peace Research Institute, 2017), https://www.sipri.org/sites/default/files/2017-06/fs_1707_wnf.pdf.

${ }^{47}$ Adeela Azam, Indian Unsafeguarded Nuclear Program: An Assessment, report (Islamabad: Institute of Strategic Studies Islamabad, 2016), 63.

${ }^{48}$ Kile and Kristensen, Trends in World Nuclear Forces.

${ }^{49}$ Gurmeet Kanwal, "Foreword," in Aftermath of a Nuclear Attack: A Case Study in Poststrike Operations (New Delhi: Pentagon Press, 2010).

${ }^{50}$ Vipin Narang, "Plenary: Beyond the Nuclear Threshold: Causes and Consequences of First Use," Carnegie International Nuclear Policy Conference, March 20, 2017, 


\section{Ayesha Abbasi}

argument is supplemented by the on-going developments by India to enhance its nuclear arsenal - which include weapon systems along a broad spectrum of ranges and yields. It is most likely that once India has acquired sufficient technological advancement, it opts for a conventional/nuclear counterforce strategy vis-à-vis Pakistan. ${ }^{51}$

Currently, India's arsenal comprises of a triad including weapon systems like Prithvi short-range ballistic missiles, intermediate and intercontinental versions of the Agni ballistic missile; nuclear glide bombs carried on aircrafts; and K-4 and K-15 missiles which are submarinelaunched ballistic missiles (SLBMs) and may be deployed on conventional or nuclear ballistic missile submarines (SSBs or SSBNs, respectively). It has already ventured into the development of nuclearpowered submarines. INS Arihant, the first indigenously designed SSBN, underwent sea trials in 2016, ${ }^{52}$ was officially inducted in the active naval force in 2018. India claims to have tested K-4 missile from INS Arihant, ${ }^{53}$ making sea-based threat a reality. A second SSBN is near completion and is expected to be launched soon. Table 1 represents the main characteristics of India's land- and sea-based ballistic missiles:

https://fbfy83yid9j1dqsev3zq0w8n-wpengine.netdna-ssl.com/wpcontent/uploads/2013/08/Vipin-Narang-Remarks-Carnegie-Nukefest-2017.pdf.

51 "India's Strategic Nuclear and Missile Programmes-A Baseline Study," Center for Science and Security Studies, June 21, 2017, https://www.kcl.ac.uk/news/indiasstrategic-nuclear-and-missile-programmes-a-baseline-study.

${ }^{52}$ Gurmeet Kanwal, "India's Nuclear Force Structure 2025," Carnegie Endowment for International Peace, June 30, 2016, https://carnegieendowment.org/2016/06/30/india-snuclear-force-structure-2025-pub-63988.

53 "Nuclear-capable K-4 Ballistic Missile tested from INS Arihant," First Post, April 13, 2016, https://www.firstpost.com/india/nuclear-capable-k-4-ballistic-missile-tested-fromins-arihant-2727516.html. 
India's Nuclear Minimalism: Looking Through the Smokescreen

\section{Table-1}

India's Nuclear Forces (as of 2018)

\begin{tabular}{|c|c|c|c|c|c|}
\hline Type & $\begin{array}{l}\text { Number of } \\
\text { Launchers }\end{array}$ & $\begin{array}{c}\text { Year } \\
\text { Deployed }\end{array}$ & $\begin{array}{c}\text { Range } \\
\text { (Kilometres) }\end{array}$ & $\begin{array}{c}\text { Warhead } \\
\text { x Yield } \\
\text { (Kilotons) }\end{array}$ & $\begin{array}{l}\text { Number of } \\
\text { Warheads }\end{array}$ \\
\hline \multicolumn{6}{|c|}{ Land-based Ballistic Missiles } \\
\hline Prithvi-II & $\sim 24$ & 2003 & $350^{\bullet \bullet}$ & $1 \times 12$ & $\sim 24$ \\
\hline Agni-I & $\sim 20$ & $2007^{\bullet \bullet \bullet}$ & $700+$ & $1 \times 40$ & $\sim 20$ \\
\hline Agni-II & $\sim 8$ & $2011^{\bullet \bullet \bullet \bullet}$ & $2,000+$ & $1 \times 40$ & $\sim 8$ \\
\hline Agni - III & $\sim 8$ & $2014 ?$ & $3,200+$ & $1 \times 40$ & $\sim 8$ \\
\hline Agni - IV & n.a. & (2018) & $3,500+$ & $1 \times 40$ & n.a. \\
\hline Agni - V & n.a. & $(2020)$ & $5,200+$ & $1 \times 40$ & n.a. \\
\hline Sub-total & $\sim 60$ & & & & $\sim 60 \cdots$ \\
\hline \multicolumn{6}{|c|}{ Sea-Based Ballistic Missiles } \\
\hline Dhanush & 2 & 2013 & 400 & $1 \times 12$ & 4 \\
\hline K-15 & (12) & (2018) & 700 & $1 \times 12$ & (12) \\
\hline K-4 & (4) & $?$ & 3,500 & $1 \mathrm{x}$ & 0 \\
\hline Sub-total & (18) & & & & (16) \\
\hline Total & & & & & $130-140$ \\
\hline
\end{tabular}

Notes from source:

- $\quad$ Range listed is unrefuelled combat range with drop tanks.

- US NASIC has estimated the range as 250 kilometers (155 miles) but we assume the range has probably been increased to about 350 kilometers ( 217 miles) as stated by the Indian government

.. Agni I first began induction with the $334^{\text {th }}$ Missile Group in 2004 but did not become operational until 2007.

... Agni II first began induction with the $335^{\text {th }}$ Missile Group in 2008 but did not become operational until 2011

•... The missile and warhead inventory may be larger than the number of launchers, some of which can be reused to fire additional missiles. This table assumes an average of one warhead for each launcher.

.... In addition to the 124 warheads estimated to be assigned to fielded launchers, warheads for additional K-15 SLBMs, Agni-III MRBMs, and future Agni-IV MRBMs may already have been produced for an estimated total stockpile of 130-140 warheads.

${ }^{54}$ Hans M. Kristensen and Matt Korda, "Indian Nuclear Forces, 2018," Bulletin of Atomic Scientists 74, no. 6 (2018): 361-366, doi:10.1080/00963402.2018.1533162. 


\section{Ayesha Abbasi}

Moreover, officials and analysts continue to advocate India's aversion to Tactical Nuclear Weapons (TNWs) because of the associated use them or lose them dilemma, and the lowering of nuclear use threshold that they entail. ${ }^{55}$ Most of these arguments are presented in the context of Pakistan's development of its short-range low yield Nasr in 2011. India tested its tactical weapon Prahaar - which according to its press releases is capable of carrying both nuclear and conventional warheads ${ }^{56}$ - just three months after Pakistan tested Nasr. ${ }^{57}$ However, later data showed that development had been underway for two years prior to Nasr testing..$^{58}$ It can, hence, be safely assumed that India's venture into tactical weapons production was not in response to Pakistan's development. Prahaar's ability to carry nuclear warheads also greatly undermines India's stance of considering its nuclear weapons as only 'political' weapons without any military application. India also proposes that its nuclear weapons are strictly under civilian control - much in line with minimalistic approach - and the military is kept away from relevant decision-making. However, as the general argument goes, TNWs are battlefield weapons. Their credibility only comes from the notion that they would be deployed in the battlefield under a partial - if not fully — pre-delegated command; and secondly, from the will to use these weapons during a conflict. So, if India still posits its nuclear weapons as being 'political' tools and non-usable, it itself diminishes their credibility. Still, if it declares the will to use tactical weapons, its so-called pacifist credentials, and most importantly, its minimalistic posture loses its authority.

\footnotetext{
55 Kanwal, "India's Nuclear Force Structure 2025."

56 "Prahaar'- New Surface to Surface Tactical Missile Successfully launched," Defence Research and Development Organization (DRDO), press release, July 21, 2011, https://drdo.gov.in/drdo/English/dpi/press_release/PressReleasePraharnew.pdf.

${ }^{57}$ Ryan W. French, "Pakistan's Tactical Nuclear Weapons: Implications for Strategic Stability in South Asia," Journal of National Security Studies (2015): 17 https://www.researchgate.net/publication/319365628_Pakistan's_Tactical_Nuclear_Wea pons_Implications_for_Strategic_Stability_in_South_Asia.

${ }^{58}$ Zahir Kazmi, "SRBMs, Deterrence and Regional Stability in South Asia: A Case Study of Nasr and Prahaar," (2012), https://www.academia.edu/6596900/CONTENTS_Introduction_1_SRBMs_DETERRE NCE_AND_REGIONAL_STABILITY_IN_SOUTH_ASIA_A_CASE_STUDY_OF_N ASR_AND_PRAHAAR.
} 
New Delhi is also investing in Multiple Independently targetable Re-entry Vehicles (MIRVs) capability which has been touted as a force multiplier by its officials. ${ }^{59}$ It is working to achieve decreased response time - bringing it down to minutes — by making the missiles more mobile. ${ }^{60}$ This is being done by using cannistered Transportable Erector Launchers. Such developments show that India's leadership has opted for these capabilities because of their war-fighting nature, and is rapidly moving further away from its stated ideals of minimalism and policy of minimum deterrence. ${ }^{61}$

Another development that is likely to destabilise regional stability - while facilitating a potential first strike approach, should India chose to revise its NFU policy - is the Ballistic Missile Defence (BMD) system. While BMD worldwide is projected as being stabilising in nature, it essentially has destabilising capability. The presence of BMD can instil a false sense of security in the holder, who may then opt for a nuclear first strike thinking that any retaliatory attack by the adversary could be intercepted through the BMD. In India's case, such a scenario is not hard to imagine. It has been observed by numerous analysts that this technology — even though not fully developed by India — may embolden it to pursue aggressive designs. This may also be through implementation of conventional strategies like its Cold Start Doctrine (CSD). ${ }^{62}$ More importantly, BMD is another contradiction not only of its nuclear doctrine but also the concept of minimalism. As Rajagopalan writes:

\footnotetext{
59 "Plans to Equip Agni-V with Multiple Warheads: DRDO Chief," Deccan Herald, May 1, 2012, https://www.deccanherald.com/content/248431/plans-equip-agni-vmultiple.html.

60 "New DRDO Chief Reveals India's Plan to Reduce Current Response Time for Second N-Strike,” India Today, July 4, 2013, https://www.indiatoday.in/india/video/drdocurrent-response-time-for-second-n-strike-421556-2013-07-04

${ }^{61}$ Hans M. Kristensen, "India's Missile Modernization Beyond Minimum Deterrence," Federation of American Scientists, October 4, 2013, https://fas.org/blogs/security/2013/10/indianmirv/.

${ }^{62}$ Zafar Nawaz Jaspal, "Ballistic Missile Defense: Implications for India-Pakistan Strategic Environment," NDU Journal (2011):15, http://ndu.edu.pk/issra/issra_pub/articles/ndu-journal/NDU-Journal-2011/01-BallisticMissile-Defence.pdf.
} 
Ayesha Abbasi

There would be no clearer indicator that BMDs do not fit well within Indian strategic thought than the fact that no Indian doctrinal statements - neither the Draft Indian Nuclear Doctrine of the NSAB nor the official statement about India's nuclear doctrine that the Prime Minister's Office (PMO) released in early January 2003 - even hint at the need for BMDs. In fact, I would go further: a decision to acquire such an ABM system directly contradicts the basis of the Indian nuclear doctrine. ${ }^{63}$

\section{Disarmament}

Disarmament is an important tenet of nuclear minimalism, and found a mention in DND and the 2003 doctrinal document. Even before India had acquired the technology necessary to develop nuclear weapons, it refused to support programmes like the US Baruch Plan (1945) and international safeguards systems - that could potentially prevent it from acquiring nuclear capability. All this was done while both Nehru and Bhabha continued to campaign for a world free of nuclear weapons. ${ }^{64}$

While on the one hand, India to date continues to support the idea of a world free of nuclear weapons, it keeps its support withdrawn from initiatives like the NPT, Comprehensive Nuclear-Test Ban Treaty (CTBT), and negotiations on a Fissile Material Cutoff Treaty (FMCT).

India cites NPT as being discriminatory in nature and calls 'global, verifiable, and non-discriminatory nuclear disarmament' a national security objective. ${ }^{65}$ Furthermore, while it has been observing a unilateral moratorium on nuclear testing since 1998, it has refrained from signing the CTBT. There are two schools of thought in the country's strategic community which came forward once the debate on whether or not India should sign CTBT began. One group supports the idea of sustaining a reasonably credible deterrent, without the need for testing. Whereas the

${ }^{63}$ Ibrahim Anjum, "Implications of Indian Ballistic Missile Defence (BMD) on Strategic Stability," Policy Perspectives 13, no. 1 (2016): 104, doi:10.13169/polipers.13.1.0097.

${ }^{64}$ C. Raja Mohan, "India and Nuclear Weapons," International Politics and Society (1998): 378, https://library.fes.de/pdf-files/ipg/ipg-1998-4/artmohan.pdf.

${ }^{65}$ MoEAI "Draft Report of the National Security Advisory Board (NSAB) on the Indian Nuclear Doctrine." 
other group — which comprises primarily of technical experts — argues that in order for India's deterrent to remain credible, testing is necessary ${ }^{66}$

On FMCT, India supports a treaty that does not cover existing stockpiles. Such a treaty, if implemented would not substantially contribute towards attaining the objective of nuclear disarmament. A treaty which does not cover existing stockpiles will certainly provide New Delhi with a strategic advantage as it already has considerable amount of nuclear fuel available for its strategic advancements. ${ }^{67}$ Moreover, current position and statements taken at the Conference on Disarmament (CD) help project its image as a responsible NWS. However, its position may change once the current impasse on FMCT negotiations break and any developments occur - primarily because even though it possesses sufficient existing stockpiles, conclusion of such a treaty may hamper the development of its nuclear triad. ${ }^{68}$

At the United National General Assembly (UNGA), since the 1990s, India has called for the establishment of a 'Convention on the Prohibition of the Use of Nuclear Weapons', and has also introduced a resolution to this end. The resolution calls for 'reaffirming that any use of nuclear weapons would be a violation of the Charter of the United Nations and a crime against humanity' while continuing to propose that the 'Conference on Disarmament to commence negotiations in order to reach agreement on an international convention prohibiting the use or threat of use of nuclear weapons under any circumstances. ${ }^{69}$ While such actions may seem to be in line with its ideals of nuclear minimalism, they are in stark contrast to its current policy of massive retaliation. Moreover, the current debate on revision of India's NFU pledge also undermines such initiatives taken in the past. Additionally, the state further tarnished its

\footnotetext{
${ }^{66}$ Mohan, "India and Nuclear Weapons."

${ }^{67}$ Sameer Ali and Tanzeela Khalil, "Debating Potential Doctrinal Changes in India's Nuclear Ambitions," IPRI Journal XVIII, no. 2 (2018): 66, doi.org/10.31945/iprij.180203.

${ }^{68}$ Ibid.

${ }^{69}$ Sundarama and Ramana, "India and the Policy of No First Use of Nuclear Weapons," 163.
} 


\section{Ayesha Abbasi}

image as a so-called responsible and "reluctant ${ }^{70}$ NWS when it joined all the other such states in boycotting the Treaty on the Prohibition of Nuclear Weapons (TPNW). ${ }^{71}$

\section{Conclusion}

It is difficult to understand any country's current and future trajectory of policy-making and its definition of the parameters of national security without studying the policy-making framework employed by its leaders throughout its history. This article aimed to do so by taking India as a case study and looking at its policy-making in the nuclear domain, as well as the thought process that drove (and continues to do so) the formation of said policies. The historical context presented paves way for understanding the duality in India's policy circles which manifests itself in the policies that are eventually made.

India is torn between trying to simultaneously project its pacifist and non-pacifist credentials of statecraft. It finds itself struggling to maintain a balance between minimalism - advocated by its founder Mahatma Gandhi as a way of life and later taken up by his successors as a nuclear policy - and the growing understanding of itself as a nation at par with global powers.

India opted for nuclear minimalism to project a positive image worldwide. It devoted itself to NFU as a commitment; CMD as a policy; and eventual disarmament as a goal. However, critically analysing the major events in its nuclear history, the actions, decisions, and statements of its nuclear policy-making elite draw a clear picture marred with duality and contradiction. The country and its leaders have used these positions as tools to project an image of being a responsible NWS internationally. However, just like prestige and domestic politics were the drivers behind the state's acquisition of nuclear weapons capability, in order for it to become a regional hegemon, these factors continue to drive its

\footnotetext{
${ }^{70}$ Vipin Narang, "India's Nuclear Strategy Twenty Years Later: From Reluctance to Maturation," India Review 17, no. 1 (2018): 159-179, doi:10.1080/14736489.2018.1415289. .

71 "Nuclear Disarmament India," Nuclear Threat Initiative, January 2, 2019, https://www.nti.org/analysis/articles/india-nuclear-disarmament/.
} 
India's Nuclear Minimalism: Looking Through the Smokescreen

modernisation plans which go against the idealistic standards charted under the concept of nuclear minimalism. 